\title{
Delamination toughening assisted by phosphorus in medium-carbon low-alloy steels with ultrafine elongated grain structures
}

\author{
Xiaohua Min $^{\mathrm{a}, \mathrm{b}}$, YuujiKimura ${ }^{\mathrm{b} *}$, TakashiKimura $^{\mathrm{b}}$ and Kaneaki Tsuzaki ${ }^{\mathrm{b}, \mathrm{c}}$ \\ ${ }^{a}$ School of Materials Science and Engineering, Dalian University of Technology, Dalian 116024, \\ P.R.China \\ ${ }^{b}$ National Institute for Materials Science, 1-2-1 Sengen, Tsukuba, Ibaraki 305-0047, Japan \\ ${ }^{c}$ Department of Mechanical Engineering, Kyushu University, 744 Motooka, Nishi-ku, Fukuoka \\ 819-0395, Japan
}

*Corresponding author

TEL: +81-29-859-2123

FAX:+81-29-859-2101

E-mail addresses: Kimura.Yuuji@nims.go.jp

(C) 2015. This manuscript version is made available under the Elsevier user license http://www.elsevier.com/open-access/userlicense/1.0/ 


\begin{abstract}
The effect of phosphorus (P) on delamination tougheningwas examined for $0.4 \% \mathrm{C}-1 \% \mathrm{Cr}-0.7 \% \mathrm{Mn}-0.2 \%$ Mo steels (mass $\%$ ) comprised ofultrafine elongated grain (UFEG) structures with strong $<110>/ / \mathrm{RD}$ fiber textures. The UFEG structuresevolved through the plastic deformation of tempered martensitic structuresby multi-pass caliber rolling at a temperature of $773 \mathrm{~K}$ (warm tempforming, WTF). The addition of $\mathrm{P}$, up to $0.093 \%$ (mass $\%$ ), had little influence on the evolution of the UFEG structure and the strength of the steels. Although the tensile ductility and upper-shelf energy showed a slight tendency to decreaseasthe $\mathrm{P}$ concentration increased from $0.001 \%$ to $0.093 \%$, the delaminationperpendicular to the notch orientation of the impact specimens was pronouncedover a wider temperature range. As a result of delamination, the $0.093 \%$ P-doped steel exhibited a significant inverse temperature dependence of toughness at temperatures from $250 \mathrm{~K}$ to $350 \mathrm{~K}$. The delamination toughening was dominated by the UFEG structure, and further assisted by the phosphorus segregation.It was considered that the formation of distinct $\mathrm{P}$ segregation bands, which presented a structure consisting of brittle and ductile layers, may be especially effective in accelerating delamination and improving toughness in P-doped steel with an UFEG structure.
\end{abstract}

Keywords: steel;thermomechanical treatment;ultrafine grainedmicrostructure;phosphorus segregation;delamination, toughness 


\section{Introduction}

Impurity reduction[1-3] and grain refinement[4-8]areboth recognized as effective methods for enhancing the notch toughness of high-strength steels. The former is considered to inhibit intergranular fracture, which is often owed tograin boundary segregation due to impurities such as phosphorus $(\mathrm{P})$, and the consequentloss of grain boundary cohesion[1,3].The latter is considered to increase the grain boundary area per unit volume, whichreduces the stress concentration at the grain boundaries, especially at triple junctions, and it is also considered to decrease the grain boundary segregation due to the concentration of impuritiesatthe grain boundaries.It is well known that these methods improve the intrinsic fracture resistance of high-strength steels. In addition, owing to the relaxation of the stress concentration at the crack tips,delamination perpendicular to the plane of the notchis also recognized asan effective method to improve the notch toughness at low temperatures[9-12].

Recently, Kimura et al.[13-18]have developed a thermomechanical treatment in which tempered martensitic steel is plastically deformed using multi-pass caliber rolling at an elevated temperature (i.e., warm tempforming, WTF).This treatment enhancesthe notch toughness of ultra-high-strength steel,resulting in a yield strength $\left(\sigma_{y}\right)$ of $1.4 \mathrm{GPa}$ or greater. Forexample,a $0.4 \% \mathrm{C}-2 \% \mathrm{Si}-1 \% \mathrm{Cr}-1 \% \mathrm{Mo}$ steel (all chemical compositions are expressed in mass $\%$ ) exhibited a $\sigma_{y}$ of $1.84 \mathrm{GPa}$ and a Charpy V-notch absorbed energy $(v E)$ of $226 \mathrm{~J}$ at room temperature owing to the evolution of an ultrafine elongated grain (UFEG) structure with a strong $<110>/ /$ rolling direction (RD) fiber texture during the WTF[13].Furthermore, this steel with a UFEG structuredemonstrated significant inverse temperature dependence of toughness overthe temperature range of $213 \mathrm{~K}$ to $333 \mathrm{~K}$ [13]. This enhancement of the notch toughness was due to the delaminationthat occurred perpendicular to the notch orientation of the impact specimens[13-18].It was determined that the dominant factors responsible for the delamination 
toughening were the transverse grain size, grain shape, $<110>/ / \mathrm{RD}$ fiber texture, and nanometer-sizedcarbide particle distribution in the UFEG structure[17].

Jafari et al.[19-22]also investigated the delamination tougheningofa $0.4 \% \mathrm{C}-1 \% \mathrm{Cr}-0.7 \% \mathrm{Mn}-0.2 \% \mathrm{Mo}$ steel with an addition of $0.053 \% \mathrm{P}$. They reported that the steel sample with an UFEG structure that was processed by the WTFdemonstrateda high $v E$ due to the occurrence of delamination at a temperature of $123 \mathrm{~K}$, at whichP embrittlement occurred for the conventionally quenched and tempered sample. Here, two possible reasonswereconsidered for the improvement inthe notch toughnessof the $0.053 \%$ P-doped steel with an UFEG structure. One reason is that the intergranularfracture along the prior-austenite grain boundaries, which results from the P grain boundary segregation, issuppressed through the formation of the UFEG structure[19].The other reason is that the delamination isacceleratedthrough the reductionof the interface cohesiondue tothe P segregationin the UFEG structure [20].

If this is the case, further weakening of the grain boundarywith a higher concentration of $\mathrm{P}$ may further facilitate the delamination toughening. This is a great developmentregarding the conventional metallurgical concepts of $\mathrm{P}$ embrittlement; $\mathrm{P}$ grain boundary/interface segregation is considered to be a factor that increases the impact toughness of the steel. Therefore, we need to determine whether the enhancement of the delamination toughening is greater in the steel with the higher $\mathrm{P}$ concentration, and we also need to clarify the combined influence of the UFEG structure and P segregation on the delamination toughening.

The purpose of this study is to effectively utilize the detrimental effect of $\mathrm{P}$ segregation toenhance theimpact toughnessof high-strength steels. Thus, the effects of variousconcentrations of $\mathrm{P}$, from $0.001 \%$ to $0.093 \%$, on the UFEG structure, tensile properties, and impact toughness of $0.4 \% \mathrm{C}-1 \% \mathrm{Cr}-0.7 \% \mathrm{Mn}-0.2 \% \mathrm{Mo}$ steelswill besystematically investigated. For a comparison, P-doped steels with conventionally quenched and tempered structureswill also be used. The 
delamination toughening mechanism will be discussed on the basis ofthe UFEG structure in combination with the Psegregation.

\section{Experimental procedures}

\subsection{Materials preparation}

Five ingots with different $\mathrm{P}$ concentrations, each approximately $100 \mathrm{~kg}$ in mass, were prepared by vacuum melting. Following solidification, the ingots with a thickness of about $20 \times$ $10 \mathrm{~mm}$ were homogenized at $1473 \mathrm{~K}$ for $3.6 \mathrm{ks}$, and subsequently hot-rolled into plates with a thickness of $4 \times 10 \mathrm{~mm}$. The reduction in area owed to the multi-pass hot rolling was about $80 \%$. Table 1 lists the chemical compositions ofthe steels, namely $0.018 \% \mathrm{P}$ steel, $0.068 \% \mathrm{P}$ steel, and $0.093 \% \mathrm{P}$ steel, as analyzed after hot-rolling, along with those ofthe $0.001 \% \mathrm{P}[19,21-23]$ and $0.053 \% \mathrm{P}[19-22]$ steels as a reference. The chemical compositions are similar to those of the high-strength JIS SCM 440 (AISI 4140) steel,with the exception of the highP concentration.

The plates were cut into blocks with dimensions of $120 \mathrm{~mm}(I) \times 40 \mathrm{~mm}(w) \times 40 \mathrm{~mm}(t)$. The blocks were homogenized at a temperature of $1473 \mathrm{~K}$ for $1.8 \mathrm{ks}$, and hot-rolled using a caliber roll into square bars with a cross-section of $9 \times 10^{2} \mathrm{~mm}^{2}$, followed by air cooling. The hot-rolled bars were solution treated at a temperature of $1193 \mathrm{~K}$ for $3.6 \mathrm{ks}$, followed by oil quenching to obtain a martensitic structure. The quenched bars were tempered at $773 \mathrm{~K}$ for $3.6 \mathrm{ks}$, and subsequently subjected to multi-pass caliber rolling (WTF) into square bars with a cross-section of $2 \times 10^{2} \mathrm{~mm}^{2}$, followed by air coolingto produce the UFEG structure. The reduction in area owed to the multi-pass caliber rolling was $78 \%$ over9 passes, which corresponds to an equivalent strain of 1.75 . Note that during rolling, following three passes, the bars were held in a furnace at a temperature of $773 \mathrm{~K}$ for $0.3 \mathrm{ks}$ and they were passed through the final groove twice to control the cross-sectional shape of the bars. The tempformed bars were annealed at 
$823 \mathrm{~K}$ for $3.6 \mathrm{ks}$, followed by water quenching; these were denoted as TF samples. For a comparison, some of tempformed bars were normalized at $1153 \mathrm{~K}$ for $0.6 \mathrm{ks}$, followed by air-cooling, and subsequently austenitized at $1193 \mathrm{~K}$ for $3.6 \mathrm{ks}$, followed by oil quenching to obtain a conventional quenched and tempered martensitic structure. The quenched bars were tempered at $823 \mathrm{~K}$ for $3.6 \mathrm{ks}$, followed by water quenching, (i.e., the same conditions as those of the TF samples); these were denoted as QT samples. The principal axes of the squared bar in this study were defined as illustrated in Fig.1. The axis coincident with the rolling direction is defined as the $\mathrm{RD}$, the axis coincident with the direction of the main working force at the final pass is defined as the ND, and the axis normal to the RD and ND is defined as the TD.The pole figures in Fig.1 demonstrate that the $<110>/ / \mathrm{RD}$ fiber deformationtexture provides lots of cleavage $\{100\}$ orientations parallel to the $\mathrm{RD}$ and on the planes with the angle of $\sim 45^{\circ}$ to the $\mathrm{RD}$, while it provides lots of $\{110\}$ orientations on the planes normal to the $\mathrm{RD}$.

\subsection{Mechanical testing}

Round tensile specimens (JIS-14A) with a parallel length of $42 \mathrm{~mm}$ and a diameter of 6 $\mathrm{mm}$ were cut from the squared bars along the RD. Tensile tests were conductedwith a crosshead speed of $0.85 \mathrm{~mm} / \mathrm{min}$. A non-contacting video extensometer was used to measure the tensile strainover the $30 \mathrm{~mm}$ gauge length. Small plate specimens with a parallel length of $4 \mathrm{~mm}$, a width of $3 \mathrm{~mm}$, and a thickness of $1 \mathrm{~mm}$ were machined from the squared bars at two different angles $\left(0^{\circ}\right.$ and $\left.90^{\circ}\right)$ to the RD. They were subsequently used for tensile testing at a crosshead speed of $0.11 \mathrm{~mm} / \mathrm{min}$ to investigate the tensile anisotropy. The $0.2 \%$ offset yield strength was recorded. The true fracture $\operatorname{strength}\left(\sigma_{F}\right)$ was calculated by dividing the load at fracture by the cross-sectional area of the ruptured tensile specimens[15, 17].The specimens (dimensions: 55 $\mathrm{mm}(\mathrm{l}) \times 10 \mathrm{~mm}(w) \times 10 \mathrm{~mm}(t))$ cut from the squared bars along the RDwere used for Charpy 
impact tests with a full-size $2 \mathrm{~mm}$ V-notchover thetemperature rangeof $77 \mathrm{~K}$ to $623 \mathrm{~K}$. Note that during the Charpy impact tests, the striking direction (SD) was set at an angle of approximately $45^{\circ}$ to the ND and TD of the squared bars (Fig. 1).

\subsection{Microstructural characterization}

The samples were subjected to mechanical polishing to obtain a smooth surface. Following etching, they were observed by field emission scanning electron microscopy (FE-SEM) (JEOL JSM-7001F). The planes normal to the ND (ND Planes) were observed. Following mechanical polishing, the samples were subjected to electron backscattered diffraction (EBSD) analysis and electron probe micro-analysis (EPMA). The ND plane and the plane normal to the RD (RD plane) were analyzed. The EBSD analysis was performed using a FE-SEM (JEOLJSM-6500F) equipped with an orientation imaging microscope. The EBSD measurements were conducted on a hexagonal grid with a step size of $0.05 \mu \mathrm{m}$ in an area of $25 \mu \mathrm{m} \times 25 \mu \mathrm{m}$. All the raw data were subjected to clear-up by proceduresincluding confidence index standardization and grain dilation single iteration. The inverse pole figure was calculated using the harmonic series expansion method with a series rank of 16, and orthotropic sample symmetry was enforced.Following the Charpy impact testing, the elemental distributions of the samples were mapped by EPMA(JXA-8500F) with a specific resolution of $2 \mu$ mnear the fractured region. The fractured surfaces of the tested sampleswere observed byFE-SEM.

\section{Results}

\subsection{Microstructure}

Fig.2showsthe matrix microstructures for the QT and TFsteel samples with an addition of 0.093\%P. The QT sample exhibits a typical tempered martensitic structure with equiaxed 
prior-austenite grains that are subdivided by the packetand block boundaries(Fig. 2(a)). The average prior-austenite grain size was measured to be approximately $30 \mu \mathrm{m}$. The average linear intercept length (Fig. 2(d)) for the block was $0.60 \mu \mathrm{m}$; the block boundaries were defined as grain boundarieswith a misorientation angle of $10^{\circ}$ or greater.As for the TF sample, the prior-austenite grain boundaries could no longer be recognized, and an UFEG structure with a strong $<110>/ /$ RD fiber texture had evolved (Fig. 2(b) and (e)). The UFEG structure consists of ribbon-like and rod-like grains that arealigned to the $\mathrm{RD}$ (Fig. 2(c) and(f)).For the UFEG structure, the averagelinear intercept length of the grain boundarieswith a misorientation angle of $10^{\circ}$ or greaterwas measured to be $0.40 \mu \mathrm{m}$ in the transverse direction, and $1.19 \mu \mathrm{m}$ in the longitudinal direction (//RD).In addition, the carbide microstructures of both the QT and TF samples are characterized by spheroidal particles, as shown in Fig. 3. The carbide particles of the TF sample appear to be more spherical than those of the QT sample, and their long axes were observed to be almost aligned to the RDof the TF sample.It was confirmed that the microstructural features of the $\mathrm{TF}$ samples with an addition of $0.093 \% \mathrm{P}$, including the transverse grain size, grain shape, $<110>/ /$ RD fiber texture, and carbide particle distribution were almost comparable to those ofthe $0.001 \% \mathrm{P}$ and $0.053 \% \mathrm{P}$ steels[19-23].Hence, the addition of $0.093 \% \mathrm{P}$ has little influence on the evolution of the UFEG structure during the WTF. Similarly, irrespective of the P concentration, the QT samples were confirmed to exhibit almost identicalmicrostructural features, including the block size, the prior-austenite grain size, and the carbide particle distribution.

\subsection{Tensile properties}

Fig.4 shows the variation in the tensile properties at room temperature as a function of $\mathrm{P}$ concentration. As previously reported forthe $0.001 \%$ and $0.053 \% \mathrm{P}$ steels $[19-21,23]$, it was 
characteristic that all the QT samples exhibited typical continuous yielding behavior. However, irrespective of the $\mathrm{P}$ addition, the sharp yield point phenomenonwasobserved forall the TF samples, and the $\sigma_{y}$ approximately corresponded to the upper yield stress of the TF samples. The $\sigma_{y}$ and tensile strength $\left(\sigma_{B}\right)$ of theQT and TF samples do not significantly change as the $\mathrm{P}$ concentration increases. Hence, the strengthening effect of the P addition [24] was not observed in the macroscopic tensile test results for the QT and TF samples. The average $\sigma_{B}$ of the TF samples $(1.13 \mathrm{GPa})$ is almost comparable to that of the QT samples (1.14 GPa), while the average $\sigma_{y}$ of the TF samples $(1.06 \mathrm{GPa})$ tends to be slightly higher than that of the QT samples $(1.00 \mathrm{GPa})$. Furthermore, regardless of the $\mathrm{P}$ concentration,the uniform elongation $\left(\varepsilon_{\mathrm{u}}\right)$ ofthe TF samples (7-8\%), as well as that ofthe QT samples(5-6\%) isalmost identical.Moreover,the reduction of area (RA) of the TF sample is comparable to that of the QT sample at a $\mathrm{P}$ content of $0.001 \%$, andtends to decreaseas the $\mathrm{P}$ concentration increases. However, the TF samples exhibit slightly higher ductility than thatof the QT samples at room temperature.In addition, for both the TF and QT samples, the $\sigma_{y}$ increasesas the tensile testing temperature decreasesfrom room temperature to $77 \mathrm{~K}$, irrespective of the $\mathrm{P}$ concentration, as shown in Fig. 5.As the P concentration is increased from $0.001 \%$ to $0.093 \%$, the total elongation (EL) and RAof the TF samplesdo not significantlydecreaseat a temperature of $77 \mathrm{~K}$; in contrast, the ELand RA of the QT samplesmarkedly decrease as the P concentration increases from $0.053 \%$ to $0.093 \%$. These results indicate that there is a more pronounceddifference in the ductility ofthe TF and QT samples at lower temperatures.

\subsection{Charpy impact properties}

Fig.6 shows the changesin the $v E$ as a function of $\mathrm{P}$ concentrationat room temperature (a), and the representative fracture appearances of the tested samples (b). For the QT samples, the 
$v E$ decreases considerably asthe $\mathrm{P}$ concentration increases, for example, the $v E$ decreases by $93 \mathrm{~J}$ and $7 \mathrm{~J}$ on average for the $0.001 \%$ and $0.093 \% \mathrm{P}$ steels, respectively. Conversely,for the TF samples, the $v$ Emaintains an almost constant average value of $147 \mathrm{~J}$ for the $0.001 \% \mathrm{P}$ steel and $143 \mathrm{~J}$ for $0.053 \% \mathrm{P}$ steel, and increases up to $196 \mathrm{~J}$ for the $0.093 \% \mathrm{P}$ steel. For the QT samples,the crack propagates across the central portion of the bar regardless of the $\mathrm{P}$ concentration, and develops shear lips around theedges of the $0.018 \% \mathrm{P}$ steelspecimen (Fig. 6(b)).A similar fracture appearance is exhibited bythe TF0.018\% P steel samples. However, for the $0.068 \% \mathrm{P}$ and $0.093 \% \mathrm{P}$ steels, theTF samples exhibit an erratic crack path with a component in the longitudinal direction of the bar, indicating the occurrence of crack-arrester type delamination fracture. The delamination fracture becomes more pronounced in the $0.093 \% \mathrm{P}$ steel, and the TF samples did not separateinto two pieces during the impact test, as indicated by the arrows in Fig.6(a) and (b).

In the geometry of the crack-arrester[9-11], delamination is thought to relax the triaxial stress conditions and blunt the crack tip. To fracture a material, crack re-initiation is necessary and this occurs under conditions of almost uniaxial tension; the impact specimen virtually behaves as an un-notched specimen. Additionally, it can be expected that the stress fielding effect from the formation of microcracks along the $\mathrm{RD}$ will reduce the driving force for fracture[25]. As a result, a highvEcan be achieved throughthis type of delamination[26, 27].

Fig.7shows the change inthe $v$ Eas a function of testing temperature for the TF and QT samples. Here, the upper-shelf energy for the TF samples was defined as the $v E$ at $623 \mathrm{Kfor}$ $0.093 \% \mathrm{P}$, at whichnone of the samples exhibited delamination fracture. The upper-shelf energy of theTF $0.093 \% \mathrm{P}$ steel sample $(134 \mathrm{~J})$ is slightly lower than that of the TF $0.053 \% \mathrm{P}(142 \mathrm{~J})$ and $0.001 \%$ P steel $(149 \mathrm{~J})$ samples; however, it is still higher than that of the QT $0.001 \%$ P steel sample (98 J).In addition, it should be noted that the TF samplesshowa high $v$ Eowing to the 
delamination at lower temperatures, whereas the QT samples exhibit a considerably low $v$ Eas a result ofbrittle rupture at lower temperatures.Furthermore, for the $0.001 \% \mathrm{P}$ steel, thedelaminationwas confined to a narrow temperature range in the vicinity of $123 \mathrm{~K}$ [23]. As the $\mathrm{P}$ concentration increases, the delamination occursovera wide temperature range from $123 \mathrm{~K}$ to higher temperatures; the delamination commences at $423 \mathrm{~K}$ for the $0.053 \% \mathrm{P}$ steel[20, 21], and at $523 \mathrm{~K}$ for the $0.093 \% \mathrm{P}$ steel. The $v E$ of the $0.093 \% \mathrm{P}$ steel $\mathrm{TF}$ sample exhibitsa significant inverse temperature dependence at temperaturesin the range of $250 \mathrm{~K}$ to $350 \mathrm{~K}$.The $\mathrm{TF}$ samplesthat did not separate into two pieces because of the delaminationareindicated by the data points with arrowsin the temperature range of $123 \mathrm{~K}$ to $348 \mathrm{~K}$, as shown in Fig. 7(a).Furthermore, compared to the QT $0.001 \%$ P steel sample, theTF $0.093 \%$ Psteel sample has superior impact properties. Therefore, the addition of $\mathrm{P}$ was also demonstrated to effectively control the delamination toughening of the steels with an UFEG structure, especially forthose with a $\mathrm{P}$ concentration range of $0.05 \%$ to $0.09 \%$.

\subsection{Fractrographs}

Fig.8 shows the representative fracture surfaces ofthe QT and TF samples with a $0.093 \% \mathrm{P}$ concentrationthat were subjected to testing at room temperature.Intergranular fractureoccurred along the boundaries of the prior-austenite grains of the QT sample (Fig. 8(a)). Furthermore, in the TF sample (Fig. 8(b) and (c)), the fracture mode of the delamination planes is characterized as a mixture of quasi-cleavage and intergranular fracture.The quasi-cleavage fracture region is roughly aligned along the longitudinal direction parallel to the $\mathrm{RD}$, similar to those ofthe low $\mathrm{P}$ samples that exhibited delamination [23]. As indicated by the arrows in Fig. 8(c), it can be observed that cracks tend to propagate along the grain boundaries of the UFEG structure.Similar intergranular fracture was observed on the delamination planes as a result ofthe slow strain rate 
tensile testing of the pre-hydrogen-charged notched specimens; as the hydrogen content increased, the intergranular fracturewas facilitated and the delamination cracking was enhanced[28]. Hence, it is demonstrated that the delamination fracture in the P-doped steel becomes more brittle and pronouncedbecause of the intergranular fracture, leading to the acceleration of the delamination crack propagation along the RD.

\section{Discussion}

This study further confirmed that the $0.4 \% \mathrm{C}-1 \% \mathrm{Cr}-0.7 \% \mathrm{Mn}-0.2 \% \mathrm{Mo}$ steels, even with a high P concentration of $0.093 \%$,exhibited excellent impact properties through the introduction ofan UFEG structure with a strong $<110>/ /$ RD fiber texture.For the sample with the UFEG structure, the addition of $0.093 \%$ Presulted in delamination over a wide temperature range of $123 \mathrm{~K}$ to $523 \mathrm{~K}$ (Figs. 6 and 7).In addition, owing to the delamination, a significant inverse temperature dependence of toughness was observed between temperaturesof $250 \mathrm{~K}$ to $350 \mathrm{~K}$. In this study, the delamination toughening of the P-doped steels with an UFEG structure was discussed in relation to the $\mathrm{P}$ segregation.

Fig.9 shows the delamination crack of the TF $0.093 \%$ P steel sample that underwent Charpy impact testing at $253 \mathrm{~K}$, in which a significant inverse temperature dependence of toughness was observed. The corresponding crack regions, indicated by the labels in Fig. 9(a), were mapped using EPMA, as shown in Fig. 9(b-e). Along the RD, the bands with high (red color) and low (blue and green color) P concentrations are co-existent.These mapping results indicate that delamination cracks preferentially initiate and propagate along the $\mathrm{P}$ segregation bands with high $\mathrm{P}$ concentration regions, as shown in Fig. 9(b-d). The arrow in Fig. 9(e) shows astep that formed between the delamination cracks along the P segregation bands. Fig.10 shows brittle cracks in the QT $0.093 \%$ P steel sample that underwent Charpy impact testing at $253 \mathrm{~K}$. 
Interestingly,the cracks propagated along the prior-austenite grain boundaries (Fig. 10(a)) of the QT sample without being influenced by the P segregated bands, as shown in Fig. 10(b).This may be responsible for the isotropic prior-austenite grain structureof the QT samples. Once cracks initiate at the prior-austenite grain boundaries owing to the reduction of grain boundary cohesion by the $\mathrm{P}$ segregation, the main cracks in the SD can easily propagate along the weakened boundaries. Fig.11 shows the SEM images and EPMA mappings of the delamination cracksof the TF $0.001 \% \mathrm{P}$ and $0.093 \% \mathrm{P}$ steel samples that were Charpy impact tested at $123 \mathrm{~K}$. Note that both the TF samples exhibited delamination fractures at $123 \mathrm{~K}$, andthe delamination fracture became more prominent as the $\mathrm{P}$ concentration increased.Forthe $0.093 \% \mathrm{P}$ steel, the delamination fracture is more pronounced along the distinctP segregation bands (Fig. 11(f)). Furthermore, forthe $0.001 \% \mathrm{P}$ steel, delamination occurs despite the lack of significant phosphorus segregation. These results indicate that the UFEG structure with a strong $<110>/ / \mathrm{RD}$ fiber texture in the TFsamples is a key factor for delamination to occur, which is further assisted by the P segregation.

Fig.12 shows the $\sigma_{y}, \sigma_{F}$, andRAof the small tensile specimens tested at a temperature of 77 $\mathrm{K}$, as a function ofP concentration and tensile direction. The $\sigma_{y}$ in the $\mathrm{RD}\left(\sigma_{y / R D}\right)$ is slightly higher than that in the SD $\left(\sigma_{y / / S D}\right)$. Such strength anisotropy is commonly observedfor steels with UFEG structures[14-17]. The addition of Phas little influence on the $\sigma_{y}$ in the tensile directions parallel to the RD and $\mathrm{SD}$. When the specimens were tensioned along the $\mathrm{RD}$, all the TF samples exhibited significant necking prior to failure, resulting in the large $\mathrm{RA}_{/ / \mathrm{RD}}$ and $\sigma_{\mathrm{F} / R D}(\mathrm{Fig}$. 12(a)). The degradation of the tensile ductility with $\mathrm{P}$ addition is minor in the $\mathrm{RD}$, as indicated in Fig.5.Furthermore, the $\mathrm{RA}_{/ / \mathrm{SD}}$ and $\sigma_{F / S D}$ are low, even in the $0.001 \% \mathrm{P}$ steel, and they markedly decrease with the addition of $0.02 \% \mathrm{P}($ Fig. $12(\mathrm{~b}))$. The $\mathrm{RA}_{/ / \mathrm{SD}}$ is almost zerofor the steels with a $\mathrm{P}$ concentration of $0.05 \%$ or greater, and the $\sigma_{F / S D}$ corresponds with the $\sigma_{y / S D}$. Hence, it is 
demonstrated that at a temperature of $77 \mathrm{~K}$, the effect of the $\mathrm{P}$ addition on the ductile failure is minorfor the TF samples tensioned in the RD, while for the samples tensioned in the SD, brittle fracture becomes more likely as theP concentration increases.

Brittle fracture occurs when thetensile stress in the process zone of the notch root and/or the crack tip exceeds the critical brittle fracture stress [8].When the weak interfaces are present along the RD for the V-notch impact specimen in Fig. 1, the interaction between the weak interface along the RD and the resolved normal tensile stress $\left(\sigma_{t}\right)$ along the $\mathrm{SD}\left(\sigma_{t / S D}\right)$ may cause brittle delamination[9, 11]. Fig.13 shows theYoffee diagram for the UFEG structure with a strong $<110>/ / \mathrm{RD}$ fiber texture[14,15,17], illustrating the relationship between the $\sigma_{t}$ and the cleavage fracture stress $\left(\sigma_{c f}\right)$. For the UFEG structure with a strong $<110>/ /$ RD fiber texture,the $\{100\}$ pole figure demonstrates that many $\{100\}$ cleavage planes are distributed on both the SD planes $(\perp \mathrm{SD})$ and the $45^{\circ}$ planes (which are inclined at an angle of $45^{\circ}$ to the RD). As a result of the elongated grain shape, the coherence length of the $\{100\}$ cleavage planes along the $45^{\circ}$ direction is shorter than that along the $\mathrm{RD}$, and thus, the cleavage fracture stress along the $45^{\circ}$ direction $\left(\sigma_{c / 45^{\circ}}\right)$ is greater than the cleavage fracture stress along the $\mathrm{SD}\left(\sigma_{c / S D}\right)$. Similarly, owing to the elongated grain shape and good grain boundary continuity along the RD, the intergranular fracture stress in the $\operatorname{SD}\left(\sigma_{g / / S D}\right)$ is low $[19,28]$. Hence, the weakest interfaces can be observed along the RD. Since $\{100\}$ cleavage planes scarcely exist on the RD planes normal to the RD (Fig.2), the cleavage crack will barely propagate in the SD.If the Tresca yield criterion is assumed in the process zone within the plastically yielding region of the notch root, the maximum values of the $\sigma_{t}$ along the RD and SDin the process zone can be approximated on the basis of $\sigma_{y}$ as $2.6 \times \sigma_{y}$ and $1.6 \times \sigma_{y}[16]$, respectively. When the $\sigma_{t / S D}$ exceeds the $\sigma_{c / / S D}$ below $T_{1}$, cleavagecracks initiate and propagate along the $\mathrm{RD}$, causing delamination to occur. As the temperature decreases, the $\sigma_{t / S D}$ increases and the delamination becomes more 
pronounced,enhancingthevE.Furthermore, in addition to the delamination cracking along the RD, the cleavage crack initiation and propagation along the $45^{\circ}$ direction is facilitated below $T_{2}$, in which the resolved normal tensile stress along the $45^{\circ}$ direction $\left(\sigma_{t / 45^{\circ}}\right)$ exceeds the $\sigma_{c / / 45^{\circ}}$. The delamination is subsequently suppressed, leading to a reduction of the $v E$.

Additionally, the macroscopic mode of the delamination fracture is characterized by a stepwise crack propagation in which "terraces" and "steps" are formed [15, 18, 26-27]. The terraces correspond to delamination planes and are approximately parallel to the RD (Fig.8 (b)). In the TF sample with an UFEG structure, the deflection ofthe transverse cracks and delamination was observed to occur in relation to "packet bands" that were formed through the extension of martensite packets in the RD[18]. The UFEG structure was mainly developed through the extension of martensite blocks within the packets. The crystallographic orientation and geometric arrangementof the UFEGs are relatively similar within a packet band[15, 18], and the packet band may have relatively good continuity of the $\{100\}$ cleavage planes and weak UFEG boundaries (including carbide particles). Hence, cracks can penetrate the packet band without any significant deflection, and the size of packet bands may be considered to be an effective grain size in order to control the delamination toughening in a TF steel with an UFEG structure. The reduction in the width of the packet bands can lead to the suppression of the transverse crack propagation, leading to the enhanced delamination. Since the packet band size, in addition to the packet size, correlates to the prior-austenite grainsize, the refinement of the prior-austenite grain size is an effective mechanism for this. Actually, in the $0.4 \% \mathrm{C}-2 \% \mathrm{Si}-1 \% \mathrm{Cr}-1 \% \mathrm{Mo}$ steel, the inverse temperature dependence of toughness was demonstrated to become significant at lower temperature as the prior-austenite grain size decreases in the grain size range of 50 to $600 \mu \mathrm{m}$, although the UFEG structure is almost identical[18]. In the present steel samples, the average prior-austenite grain size was about 30 
$\mu \mathrm{m}$, irrespective of the $\mathrm{P}$ concentration, and the packet band sizewasalso considered to be almost comparable.Fig. 14 shows the representative fracture surfaces of the TF samples with a $0.093 \% \mathrm{P}$ concentration that were subjected to testing at $77 \mathrm{~K}$.In addition to the quasi-cleavage fracture, intergranular fractureis observed on the delamination planes along the RD (Fig.14(a, c)). Furthermore, it should be noted that the brittle transversecracks are observed as indicated by the arrows in Fig.14 $(\mathrm{a}, \mathrm{b})$. The occurrence of the transverse cracks appears to suppress the delamination crack propagation along the $\mathrm{RD}$. The fracture mode of the brittle transverse cracks is quasi-cleavage (Fig.14 (b)).Such brittle transverse cracks are suggested to be associated with the family of $\{100\}$ planes, and were commonly observed in the TF $0.001 \% \mathrm{P}$ and $0.053 \%$ $\mathrm{P}[20]$ steel samplesthat were subjected to testing at $77 \mathrm{~K}$, in which the $v E$ showed a sharp drop (Fig. 7).

On the basis of the above Yoffee diagram (Fig. 13), it is interpreted that for the present $0.001 \% \mathrm{P}$ sample with an UFEG structure, the $\sigma_{c / / S D}$ may berelatively high (Fig.12) and high $\sigma_{t / S D}$ is required to cause brittle fracture. The difference between the $\sigma_{c / 445^{\circ}}$ and $\sigma_{c / / S D}$ is also minor. As a result, delamination may be confined to occur within a narrow temperature region in the vicinity of $123 \mathrm{~K}$ (Fig.7). Furthermore, in the P-doped steels, the P segregates to the weak interfaces, such as the grain boundaries, ferrite matrix/cementite interfaces, and $\{100\}$ planes, and consequently decreasesthe interface cohesion[20, 21].However, the ductility and toughness in the RD planes are not significantlyimpaired by the addition of P (Fig.12). Hence, thiscan provide a condition in which delamination couldoccur at higher temperaturesas theP concentration increases.Additionally, it should be noted that distinct $\mathrm{P}$ segregation bands form for the $0.093 \% \mathrm{P}$ steel sample(Figs. 9 and 11). Fig. 15 shows the $\mathrm{P}$ concentration line profiles in the TD for the TF samples with a different $\mathrm{P}$ concentration. TheP segregation bands are confirmed to becomemarkedly distinct in the $0.093 \% \mathrm{P}$ steel sample. For example, the $\mathrm{P}$ 
concentration in the regions of high $\mathrm{P}$ concentration appears to reachup to about 0.15 mass $\%$, while it is close to 0.05 mass $\%$ in the regions of low $\mathrm{P}$ concentration. This is considered to be especially effective to promote delamination toughening compared to the homogeneous distribution of P. As indicated in Figs.9 and 11, it is likely that the regionsofhighP concentrationmay become both initiation sites and propagation paths for delamination. The $\sigma_{g / / S D}$ is considered to especially decrease owing to the high $\mathrm{P}$ concentrationand the intergranular fracture along the boundaries of the UFEGs (Fig. 8)becomes more significant. As shown in Fig. 16 , the $\mathrm{P}$ segregation bands are long along the RD. This can provide a condition in which the brittle cracks propagatealong the RD without any significant deflection in the regions of high $\mathrm{P}$ concentration. Furthermore, in the regions of low P concentration, the UFEG structure may maintain high ductility and toughnessat lower temperatures, consequently suppressing thetransverse crack propagation along the $\mathrm{SD}$ and $45^{\circ}$ directions.

Therefore,enhanced delamination tougheningover a wide temperature range of $123 \mathrm{~K}$ to $523 \mathrm{~K}$ for theTF $0.093 \% \mathrm{P}$ steel sample is associated with the highly ductile UFEG structure combined with the brittleP segregated bands inherited from the solidification process of the ingot. Our strategy to enhance the toughness of high-strength steel is to arrest the propagation of themain cracks along the transverse directions in the hierarchical, anisotropic, and ultrafine grain structure[18, 29-30], in addition to suppressing the crack initiation. These findings further indicate thatthe use of the solidification structure is effective to enhance the toughness of high-strength steel with an UFEG structure.

\section{Conclusions}


The effect of the $\mathrm{P}$ concentrationon the delamination toughening of $0.4 \% \mathrm{C}-1 \% \mathrm{Cr}-0.7 \% \mathrm{Mn}-0.2 \% \mathrm{Mo}$ steels processed byWTF at a temperature of $773 \mathrm{~K}$ was evaluated by microstructural observation, tensile tests, and Charpy V-notch impact tests.The main results are summarized as follows:

(1) The addition of $0.001-0.093 \% \mathrm{P}$ had little influence on the evolution of the UFEG structure during thewarm tempforming; the transverse grain size,grain shape, $<110>/ / \mathrm{RD}$ fiber texture,and the distribution and morphology of the carbide particlesof the UFEG structures were almost comparable, regardless of the $\mathrm{P}$ concentration.

(2) The tensile properties including $\sigma_{y}, \sigma_{B}$, and $\varepsilon_{u}$ did not significantlychangeas theP concentration increased from $0.001 \%$ to $0.093 \%$, whilethe RAtended to decrease.However,at lower temperatures in particular, the RAdid not tend to significantly decease for the UFEG structure compared with the conventional quenched and tempered structure.

(3) Although the upper-shelf energyof the TF sample tended to slightlydecrease from $149 \mathrm{~J}$ to $134 \mathrm{~J}$ as the $\mathrm{P}$ concentration increased from 0.001 to $0.093 \%$, theP additionassisted delamination to occur over a wider temperature range. The TF $0.093 \% \mathrm{P}$ steel sampleexhibited a significant inverse temperature dependence of toughness at temperaturesof $250 \mathrm{~K}$ to $350 \mathrm{~K}$.

(4) The UFEG structure is a key factor for delamination toughening, and it is further assisted by $\mathrm{P}$ segregationat weak interfaces, such as grain boundaries, ferrite matrix/cementite interfaces, and $\{100\}$ planes. The formation of distinct $\mathrm{P}$ segregation bands in the highly P-doped steel may be especially effective to promote P-assisted delamination toughening, resulting in the significant inverse temperature dependence of toughness at temperatures of $250 \mathrm{~K}$ to $350 \mathrm{~K}$ in the TF $0.093 \% \mathrm{P}$ steel sample. 


\section{Acknowledgements}

The authors thank Mr. Kuroda and Mr. Taniuchi for the caliber-rolling processing of the materials, and Ms. Hirota and Mr. Nishio for theirassistance with the SEM and EPMA observations. This study was financially supportedby CREST, Japan Science and Technology Agency.

\section{References}

[1] H.Ohtani, C.J. McMahon Jr., Acta Metall. 23(1975)377-386.

[2] J.P. Materkowski, G. Krauss, Metall. Trans. A 10(1978)1643-1651.

[3] D.Bika, J.A. Pfaendtner, M. Menyhard, C.J. McMahon Jr., Acta Metall. Mater.43(1995)1895-1908.

[4] L.F. Porter, D.S. Dabkowski,Grain-size control by thermal cycling, in:J.J. Burke, V. Weiss (Eds.), Ultrafine-Grain Metals, Syracuse Univ. Press, New York, 1969, pp.133-161.

[5] R.P.M. Proctor, H.W. Paxton, Trans. ASM 62 (1969)989-999.

[6] S. Takaki, K. Kawasaki, Y.Kimura, J. Mater. Processing Tech.117(2001)359-363.

[7]N. Tsuji, S. Okuno, Y. Koizumi, Y. Minamino, Mater. Trans. 45(2004)2272-2281.

[8] J.W. Morris, Jr., ISIJ International, 48(2008)1063-1070.

[9]J.D. Embury, N.J. Petch, A.E. Wraith, E.S. Wright, Trans. Metall. Soc. AIME 239(1967) $114-118$.

[10] D. L. Bourell, Metall. Trans. A14(1983)2487-2496.

[11] D.W. Kum, T. Oyama, J. Wadsworth, O.D.Sherby, J.Mech.Phys.31(1983)173-186.

[12] B. Mintz, W.B. Morrison, Mater. Sci. Technol.23(2007)1346-1356.

[13] Y. Kimura, T. Inoue, F. Yin, K. Tsuzaki, Science320(2008)1057-1060. 
[14] Y. Kimura, T. Inoue, F. Yin, K. Tsuzaki: ISIJ Int.50(2010) 152-161.

[15]Y. Kimura, T. Inoue, Metall. Mater. Trans. A44(2013)560-576.

[16] T. Inoue, Y. Kimura, J. Mater., Sci. 48(2013)4766-4772.

[17] Y. Kimura, T. Inoue, ISIJ International55(2015)1135-1144.

[18] Y. Kimura, T. Inoue, ISIJ International 55(2015), 1762-1771.

[19] M. Jafari, Y. Kimura, Y. Ni, K. Tsuzaki, ISIJ International 50(2010) 1660-1665.

[20] M. Jafari, Y. Kimura, K. Tsuzaki, Metall. Mater. Trans. A43(2012)2453-2465.

[21] M. Jafari, Y. Kimura, K. Tsuzaki, Adv. Mater. Res. 409(2012) 231-236.

[22] M. Jafari, Y. Kimura, K. Tsuzaki, Phil.Mag. Lett. 93(2013)109-115.

[23] M. Jafari, Y. Kimura, K. Tsuzaki, Mater. Sci. Eng. A532(2012)420-429.

[24] R.A. Grange, C.R. Hribal, L.F. Porter, Metall. Trans. A8 (1977) 1775-1785.

[25] T. Inoue, Y. Kimura, Trans JSME.79(2013)1226-1238.

[26]A.J.McEvilyJr, R.H. Bush, Trans. ASM 55(1962)654-666.

[27] C.M. Yen, C.A. Stickels, Metall. Trans. 1(1970)3037-3047.

[28]Y. Nie, Y. Kimura, T. Inoue, F. Yin, E. Akiyama, K. Tsuzaki, Metall. Mater. Trans. A43(2012)1670-1687.

[29] T. Inoue, Y. Kimura, S. Ochiai, Scripta Mater.65(2011)552-555.

[30] Y. Kimura, T. Inoue, Bulletin of ISIJ 17(2012)829-835. 


\section{List of Captions:}

Table 1. Chemical compositions of $0.018 \% \mathrm{P}$ steel, $0.068 \% \mathrm{P}$ steel, and $0.093 \% \mathrm{P}$ steel along with those of $0.001 \% \mathrm{P}[19,21-23]$ and $0.053 \% \mathrm{P}[19-22]$ steels (mass \%).

Figure 1.Schematic drawing of a pair of caliber rolls and the relationship between the position of a rolled bar and animpact bar. $\{110\}$ and $\{100\}$ pole figuresare also shown for the TF sample of the $0.093 \% \mathrm{P}$ steel.

Figure 2. EBSD maps oftheQT and TF $0.093 \% \mathrm{P}$ steelsamples. Inverse pole figure maps for the RD combined with image quality maps $(a, b, c)$, andcorresponding grain boundary maps with a misorientation angle above $10^{\circ}(\mathrm{d}, \mathrm{e}, \mathrm{f})$. Inverse pole figure for the $\mathrm{RD}$ is also shown for the $\mathrm{TF}$ sample.

Figure3. SEM images showingthe morphology and distribution of carbide particles fortheQT sample (a) andTF sample (b) of the $0.093 \%$ P steel.

Figure4. Changes in the yield strength $\left(\sigma_{y}\right)$, tensile strength $\left(\sigma_{B}\right)$, uniform elongation $\left(\varepsilon_{u}\right)$, total elongation (EL), and reduction of area (RA) at room temperature, as a function ofP concentration of the QT and TF samples.

Figure5. Changes in the yield strength $\left(\sigma_{y}\right)$, total elongation (EL), and reduction of area (RA) as a function of tensile testing temperature for the $0.001 \% \mathrm{P}[23], 0.053 \% \mathrm{P}[20]$, and $0.093 \% \mathrm{P}$ steels.

Figure 6. Changes in the Charpy V-notch absorbed energy $(v E)$ at room temperature as a function of P concentration of the QT and TF samples (a), andthe fracture appearance of the impact samples after testing (b). Data points with arrows indicate that the samples did not separate into two pieces during the impact test.

Figure7. Changes in the Charpy V-notch absorbed energy $(v E)$ with testing temperature for TF and QT samples of (a) $0.093 \% \mathrm{P}$ steel, as well as the (b) $0.053 \% \mathrm{P}$ [20-21], and (c) $0.001 \% \mathrm{P}$ 
$[21,23]$ steels for comparison.Data points with arrows in (a) indicate that the samples did not separate into two pieces during the impact test.

Figure8. SEM fractrographs of theQT sample (a) andTF sample $(b, c)$ of the $0.093 \% \mathrm{P}$ steelfollowing Charpy V-notch impact testing at room temperature. The observed position of (c) is marked in (b).The arrows in(b) and (c) indicate the steps between the delamination planes and the cracks along the grain boundaries of the UFEG structure, respectively.

Figure9. SEM image (a) and EPMA mappings (b, c, d, e) for P distribution along the crack propagation paths in following Charpy impact tests at $253 \mathrm{~K}$. The observed positions of (b, c, d, e) are marked in (a).

Figure10. SEM image (a) and EPMA mapping (b) for P distribution along the crack propagation paths for theQT $0.093 \%$ P steel samplefollowing Charpy impact tests at $253 \mathrm{~K}$.

Figure 11. SEM images and EPMA mappings along the crack propagation paths for the TF $0.001 \% \mathrm{P}$ steel and $0.093 \% \mathrm{P}$ steel samples following Charpy impact tests at $123 \mathrm{~K}$. SEI images(a, d), BEI images(b, e) and EPMA mappings(c, f) for P distribution. The observed local positions for BEI and EPMA are marked in $(a, d)$.

Figure 12. Changes in the yield strength $\left(\sigma_{y}\right)$, true fracture strength $\left(\sigma_{F}\right)$, and reduction of area (RA) at a temperature of $77 \mathrm{~K}$ as a function of $\mathrm{P}$ concentration of the TF steel samples. The tensile axis is parallel to RD (a) and parallel to SD (b).

Figure 13. Yoffee diagram for UFEG structure with a strong $\{110\}$ fiber deformation texture [14, $15,17]$. Cleavage fractures on the longitudinal $\{100\}$ planes (/RD) cause delamination toughening (curve i), while those on the $\{100\}$ planes with the transverse components decrease the delamination toughening (curve ii). $\{100\}$ pole figure is also shown for the $0.093 \% \mathrm{P}$ steel sample.

Figure 14. SEM fractrographs of the TF sampleof the $0.093 \% \mathrm{P}$ steel following Charpy V-notch 
impact testing at $77 \mathrm{~K}$. The observed positions of (c) and (d) are marked in (a) and (b), respectively.The arrows in $(\mathrm{a}, \mathrm{b})$ and (c) indicate the brittle transverse cracks and the cracks along the grain boundaries of the UFEG structure, respectively.

Figure 15.Change in the $\mathrm{P}$ concentration line profile in the TD for the TF samples as a function of $\mathrm{P}$ concentration.

Figure 16.EPMA mappings for $\mathrm{P}$ distribution showing the $\mathrm{P}$ segregation band structure for the TF $0.093 \%$ P steel sample. 
Table 1. Chemical compositions of $0.018 \% \mathrm{P}$ steel, $0.068 \% \mathrm{P}$ steel, and $0.093 \% \mathrm{P}$ steel along with those of $0.001 \% \mathrm{P}[19,21-23]$ and $0.053 \% \mathrm{P}$ [19-22] steels (mass \%).

\begin{tabular}{|c|c|c|c|c|c|c|c|c|c|c|}
\hline Steels & $\mathrm{C}$ & $\mathrm{Si}$ & $\mathrm{Mn}$ & $\mathrm{Cr}$ & $\mathrm{Mo}$ & $\mathrm{Al}$ & $\mathrm{P}$ & $\mathrm{S}$ & $\mathrm{O}$ & $\mathrm{N}$ \\
\hline \hline $0.001 \% \mathrm{P}$ & 0.40 & 0.24 & 0.73 & 1.04 & 0.22 & 0.022 & 0.001 & $<0.001$ & $<0.004$ & 0.003 \\
\hline $0.018 \% \mathrm{P}$ & 0.40 & 0.24 & 0.70 & 0.99 & 0.20 & 0.022 & 0.018 & $<0.0005$ & 0.001 & 0.002 \\
\hline $0.053 \% \mathrm{P}$ & 0.42 & 0.25 & 0.72 & 0.98 & 0.20 & 0.003 & 0.053 & 0.001 & 0.001 & 0.004 \\
\hline $0.068 \% \mathrm{P}$ & 0.40 & 0.25 & 0.71 & 1.01 & 0.20 & 0.022 & 0.068 & $<0.0005$ & 0.001 & 0.002 \\
\hline $0.093 \% \mathrm{P}$ & 0.41 & 0.24 & 0.71 & 1.00 & 0.20 & 0.022 & 0.093 & 0.0005 & 0.001 & 0.001 \\
\hline
\end{tabular}




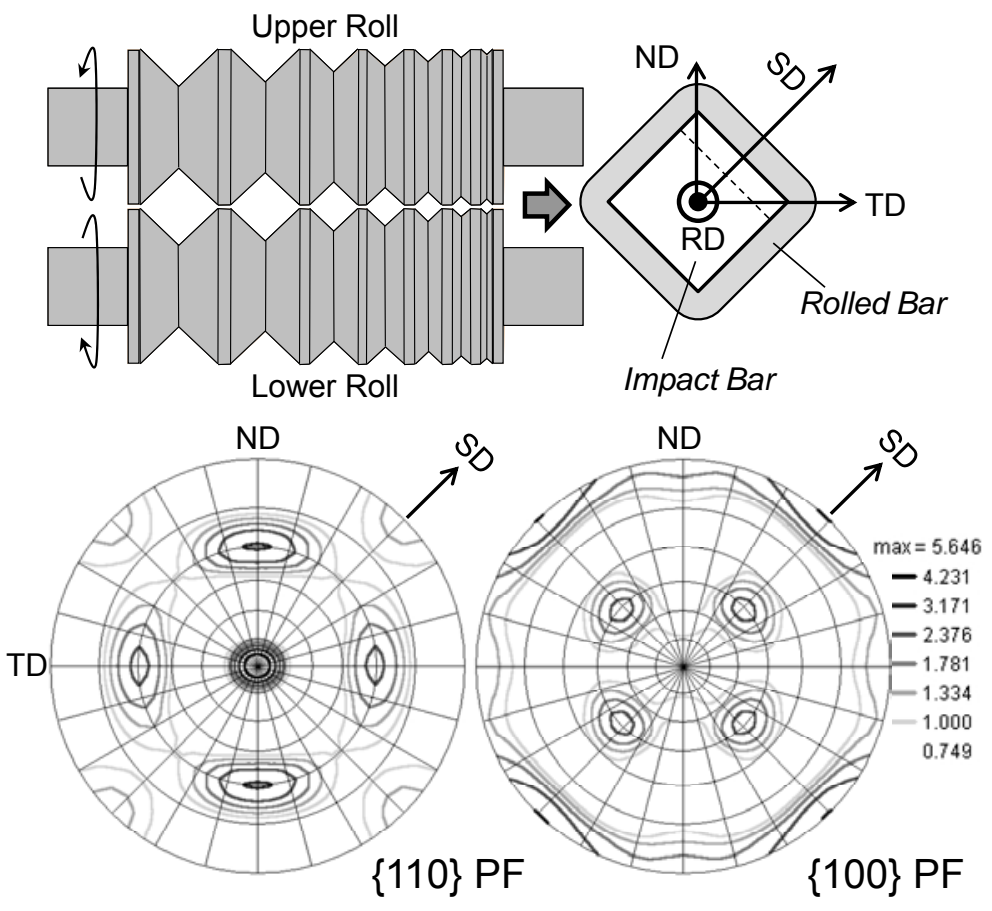

Figure 1.Schematic drawing of a pair of caliber rolls and the relationship between the position of a rolled bar and animpact bar. $\{110\}$ and $\{100\}$ pole figuresare also shown for the TF sample of the $0.093 \%$ P steel. 

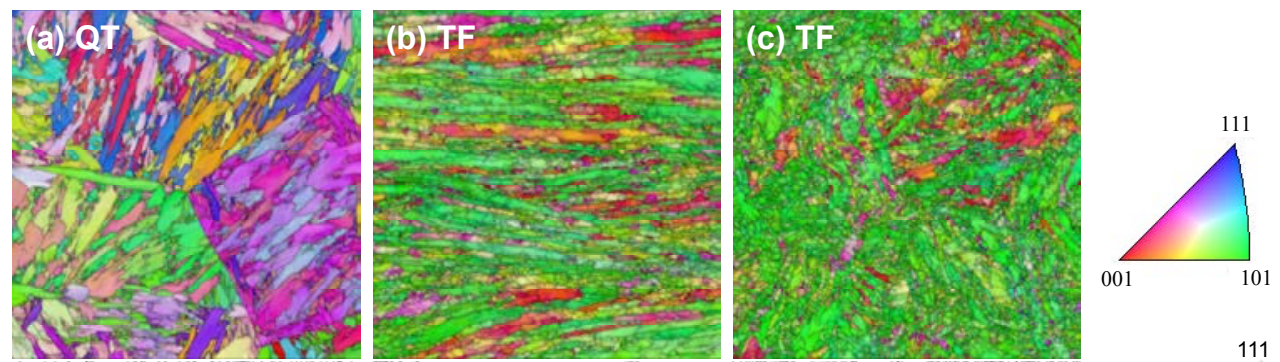

(d) QT

(e) TF

(f) TF
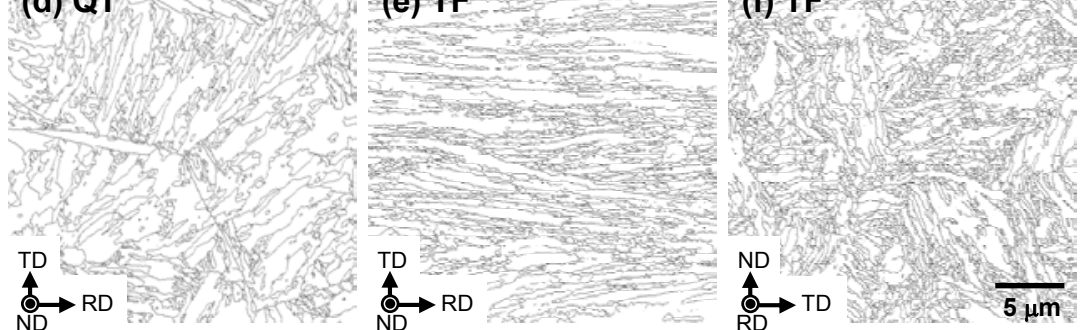

I/RD

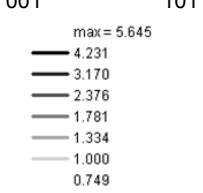

Figure 2. EBSD maps of the QT and TF $0.093 \% \mathrm{P}$ steel samples. Inverse pole figure maps for the RD combined with image quality maps $(a, b, c)$, and corresponding grain boundary maps with a misorientation angle above $10^{\circ}(\mathrm{d}, \mathrm{e}, \mathrm{f})$. Inverse pole figure for the $\mathrm{RD}$ is also shown for the TF sample. 

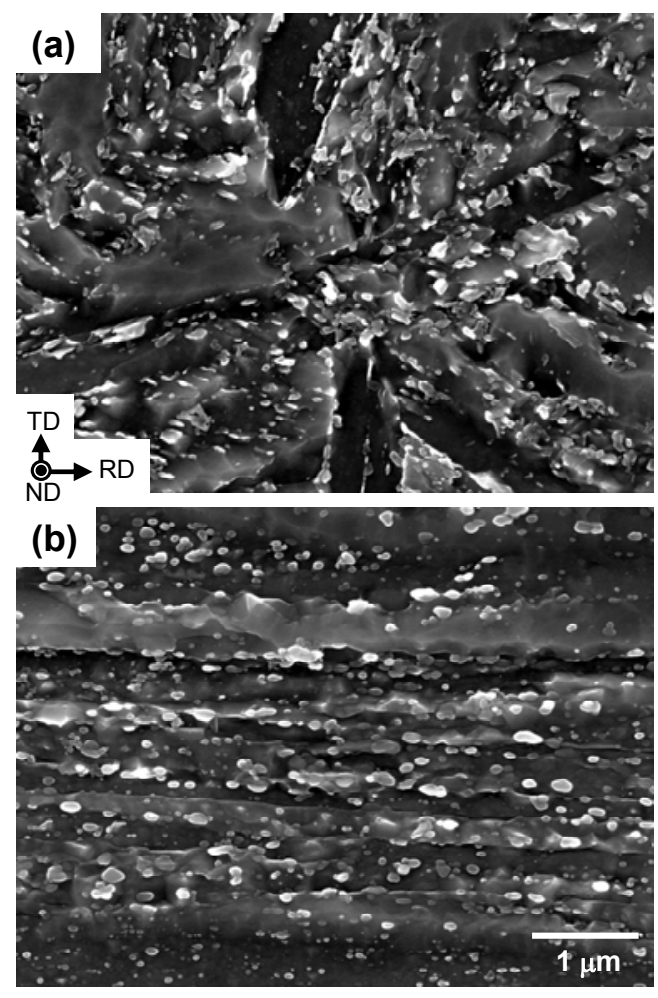

Figure 3. SEM images showing the morphology and distribution of carbide particles for the QT sample (a) and TF sample (b) of the $0.093 \%$ P steel. 


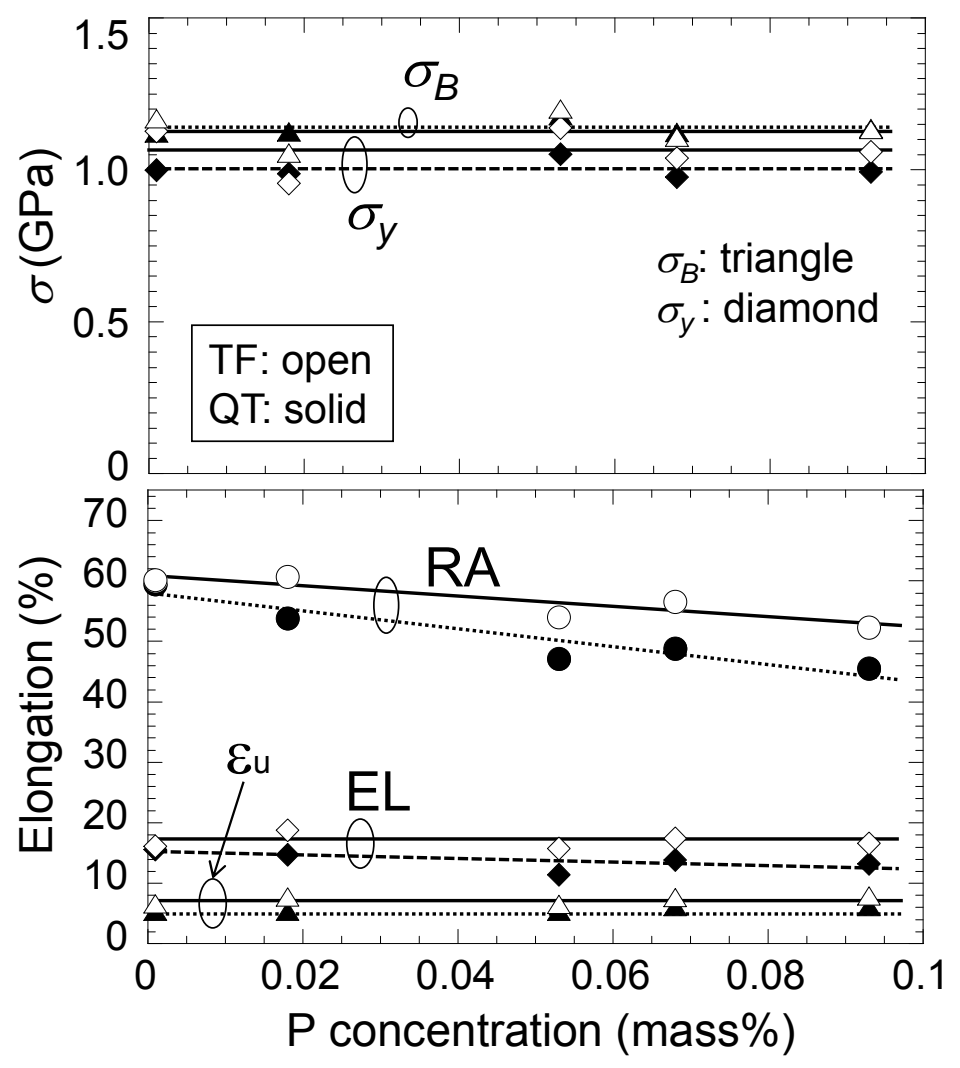

Figure4. Changes in the yield strength $\left(\sigma_{y}\right)$, tensile strength $\left(\sigma_{B}\right)$, uniform elongation $\left(\varepsilon_{u}\right)$, total elongation (EL), and reduction of area (RA) at room temperature, as a function of $\mathrm{P}$ concentration of the QT and TF samples. 


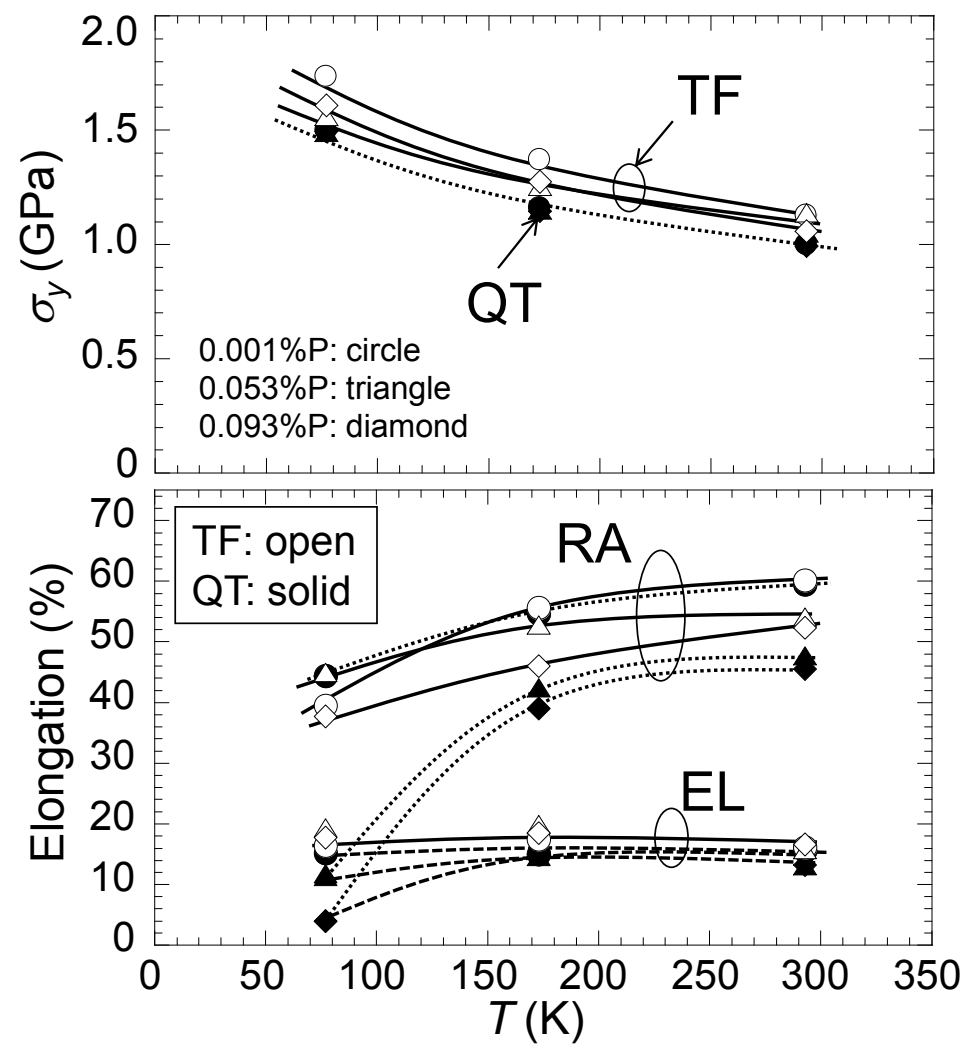

Figure 5. Changes in the yield strength $\left(\sigma_{y}\right)$, total elongation (EL), and reduction of area (RA) as a function of tensile testing temperature for the $0.001 \% \mathrm{P}$ [23], $0.053 \% \mathrm{P}$ [20], and $0.093 \% \mathrm{P}$ steels. 


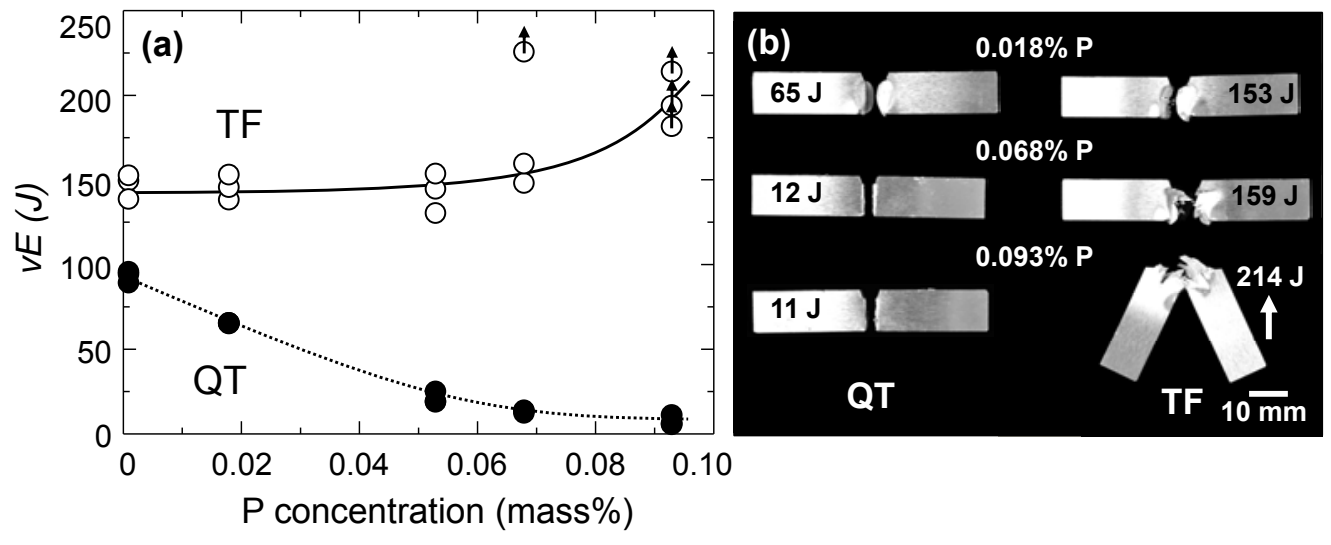

Figure 6. Changes in the Charpy V-notch absorbed energy $(v E)$ at room temperature as a function of $\mathrm{P}$ concentration of the QT and TF samples (a), and the fracture appearance of the impact samples after testing (b). Data points with arrows indicate that the samples did not separate into two pieces during the impact test. 

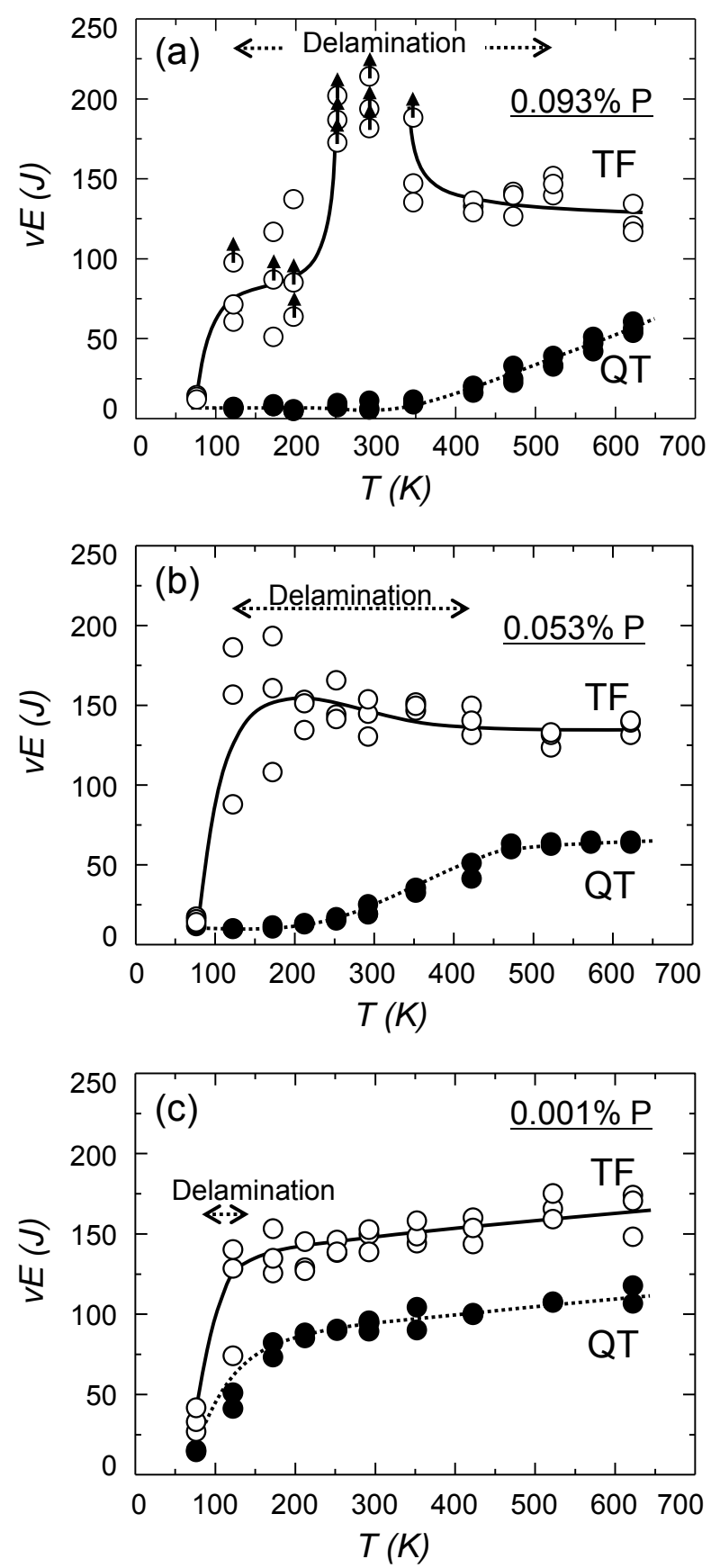

Figure 7. Changes in the Charpy V-notch absorbed energy $(v E)$ with testing temperature for TF and QT samples of (a) $0.093 \%$ P steel, as well as the (b) $0.053 \%$ P [20-21], and (c) $0.001 \%$ P $[21,23]$ steels for comparison. Data points with arrows in (a) indicate that the samples did not separate into two pieces during the impact test. 

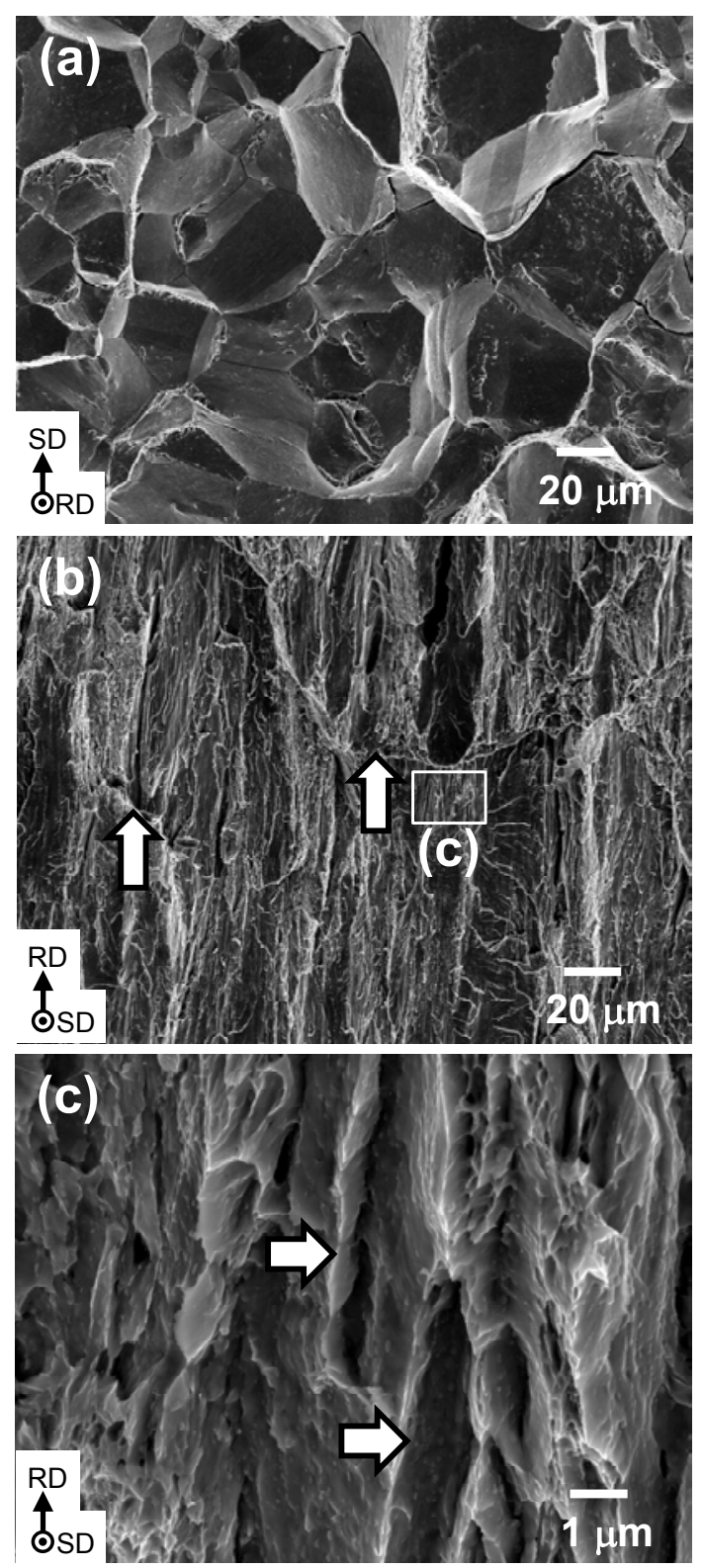

Figure 8. SEM fractrographs of the QT sample (a) and TF sample (b, c) of the $0.093 \% \mathrm{P}$ steel following Charpy V-notch impact testing at room temperature. The observed position of (c) is marked in (b).The arrows in(b) and (c) indicate the steps between the delamination planes and the cracks along the grain boundaries of the UFEG structure, respectively. 

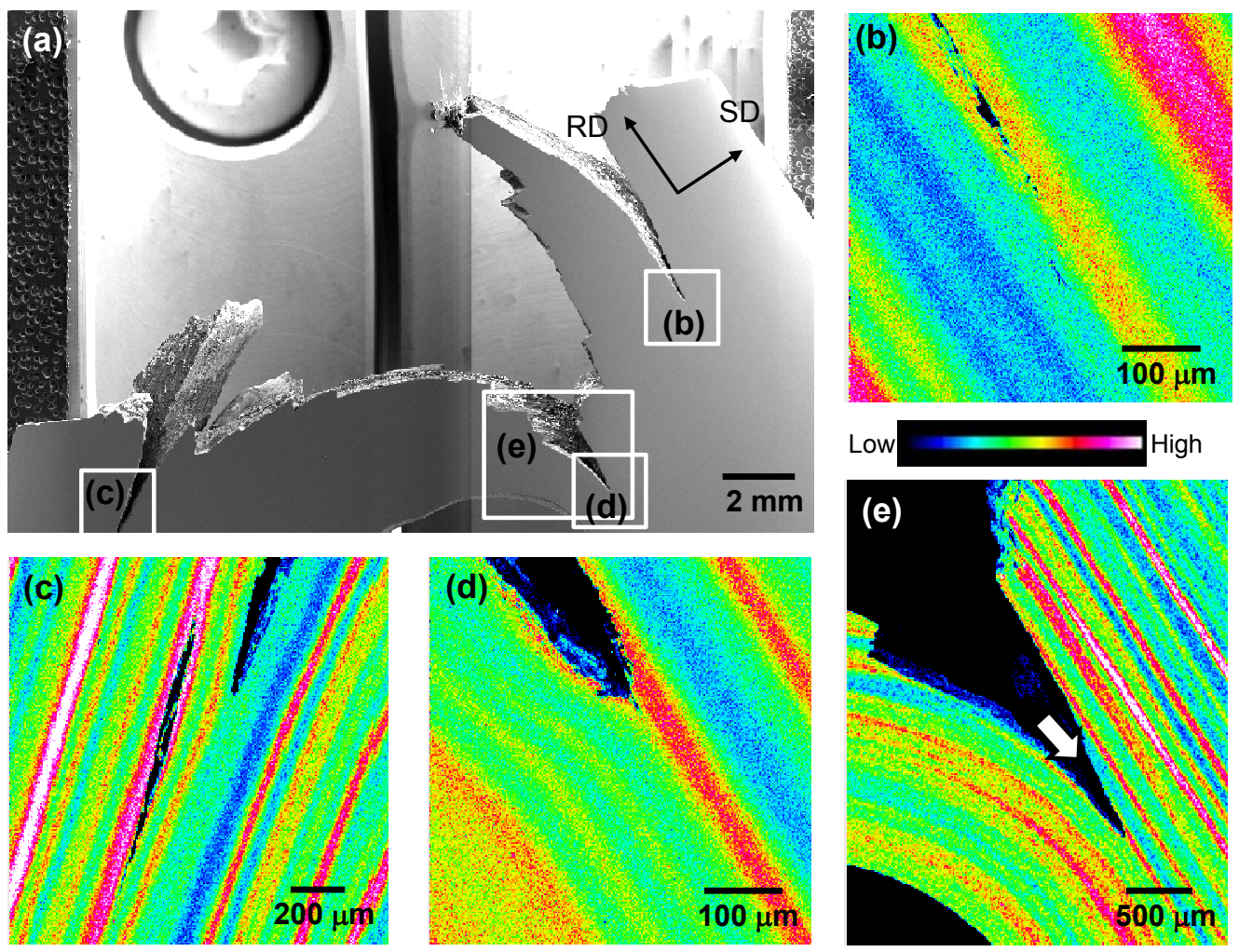

Figure 9. SEM image (a) and EPMA mappings (b, c, d, e) for P distribution along the crack propagation paths in following Charpy impact tests at $253 \mathrm{~K}$. The observed positions of (b, c, d, e) are marked in (a). 

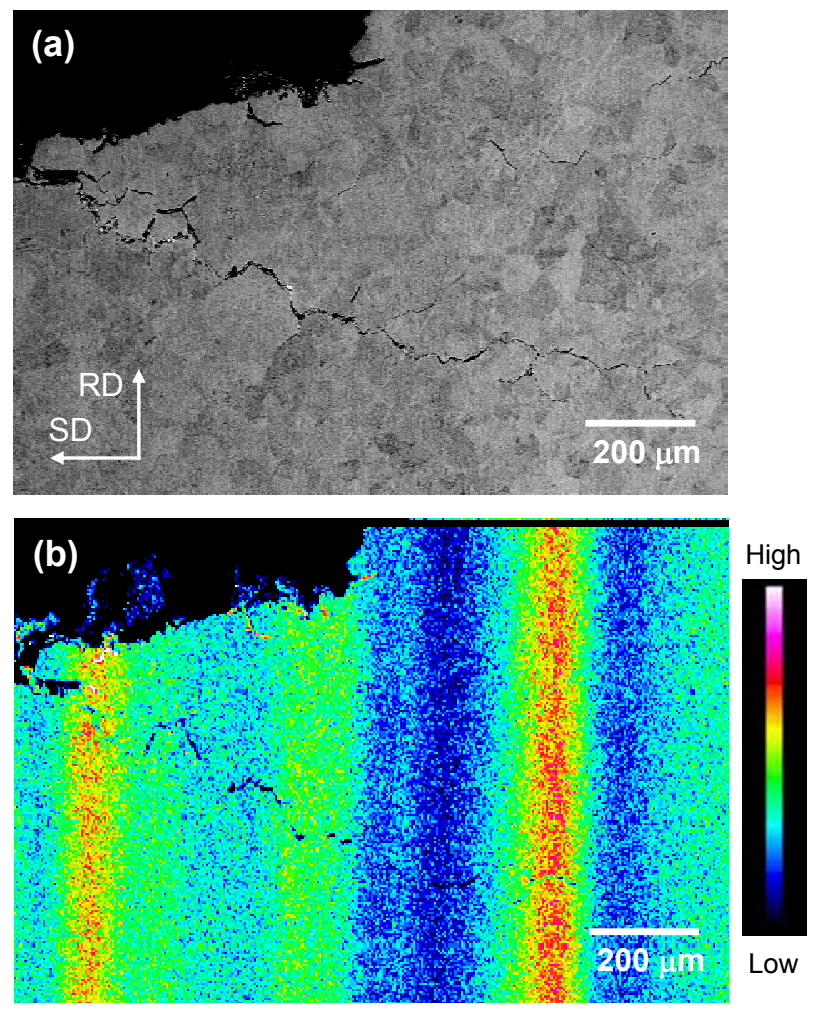

Figure 10. SEM image (a) and EPMA mapping (b) for $\mathrm{P}$ distribution along the crack propagation paths for the QT $0.093 \%$ P steel sample following Charpy impact tests at $253 \mathrm{~K}$. 

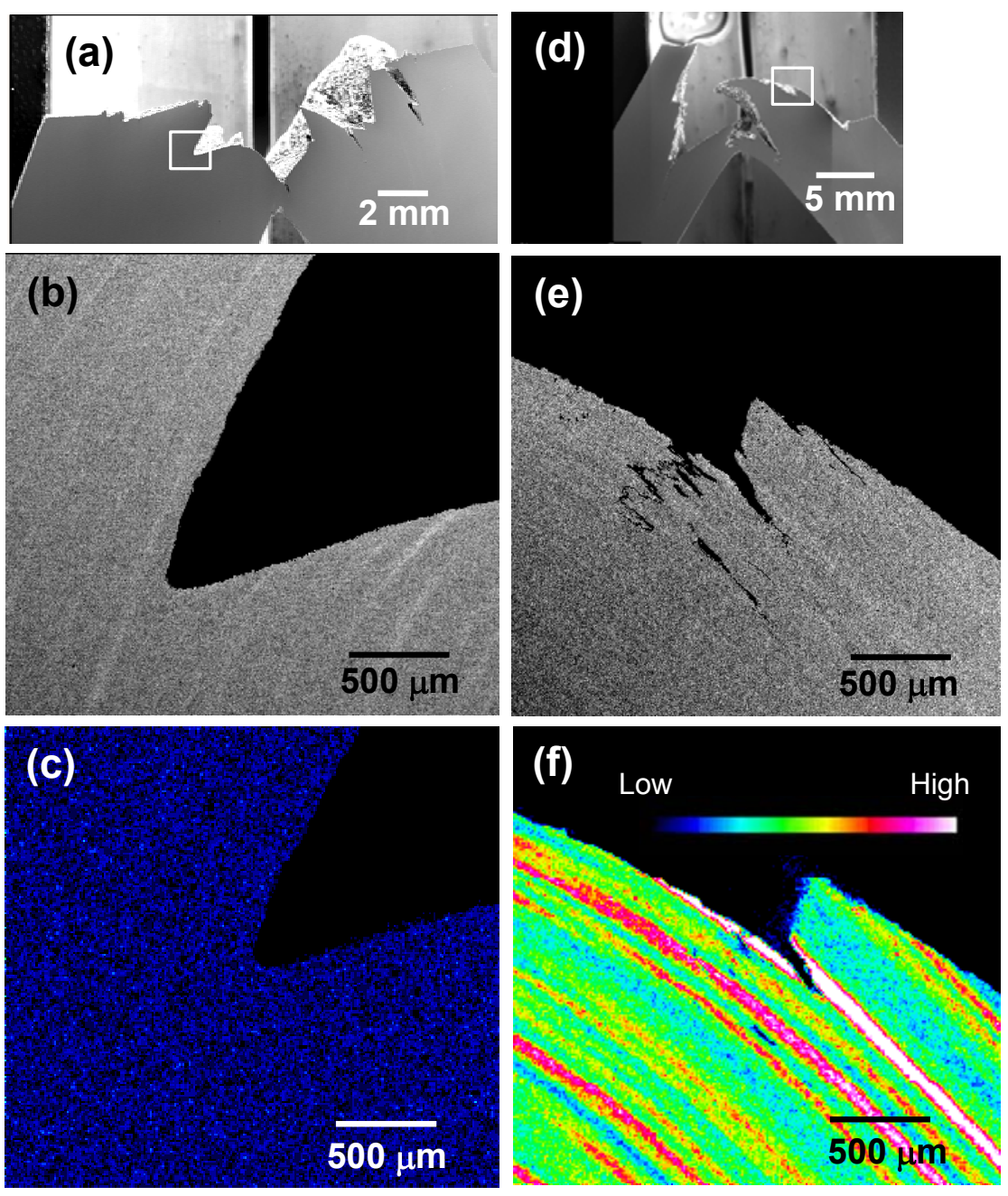

Figure 11. SEM images and EPMA mappings along the crack propagation paths for the TF $0.001 \% \mathrm{P}$ steel and $0.093 \% \mathrm{P}$ steel samples following Charpy impact tests at $123 \mathrm{~K}$. SEI images (a, d), BEI images (b, e) and EPMA mappings (c, f) for P distribution. The observed local positions for BEI and EPMA are marked in $(a, d)$. 

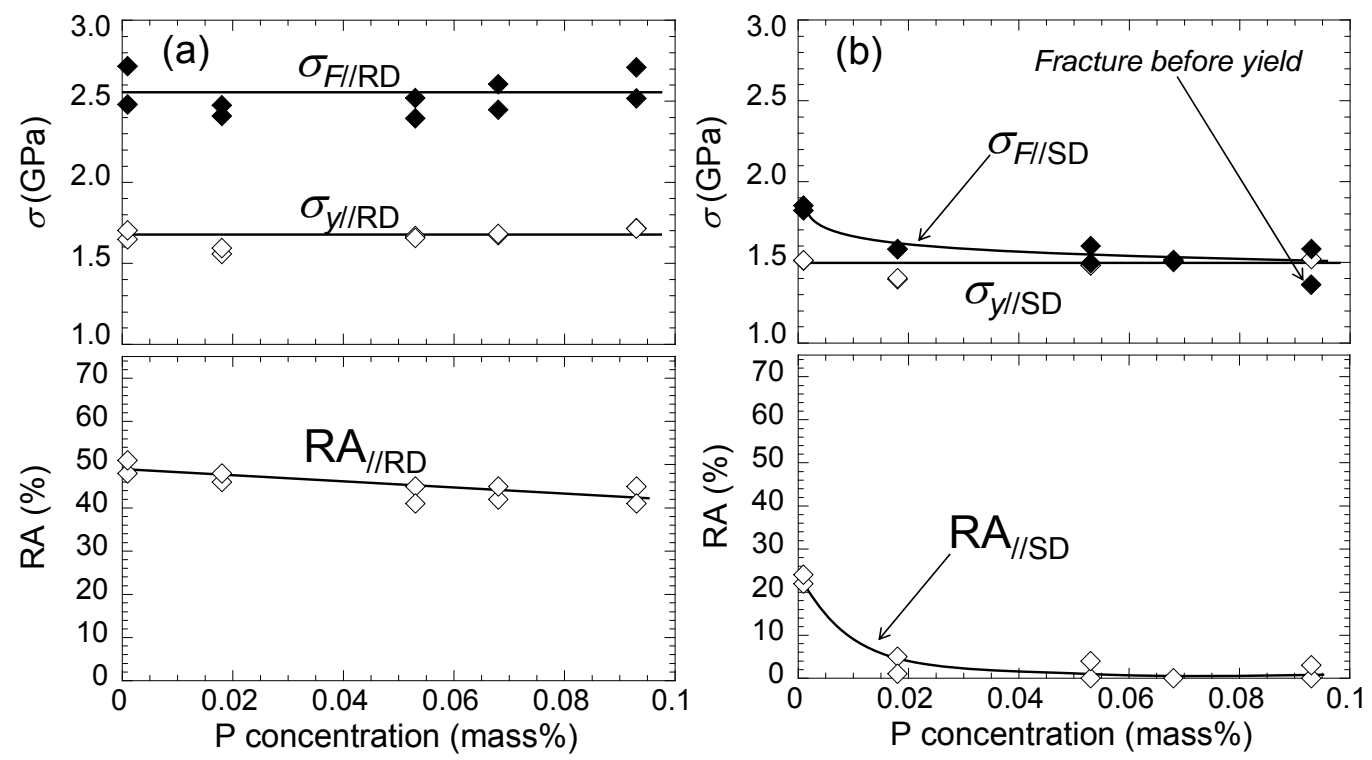

Figure 12. Changes in the yield strength $\left(\sigma_{y}\right)$, true fracture strength $\left(\sigma_{F}\right)$, and reduction of area (RA) at a temperature of $77 \mathrm{~K}$ as a function of $\mathrm{P}$ concentration of the TF steel samples. The tensile axis is parallel to RD (a) and parallel to SD (b). 


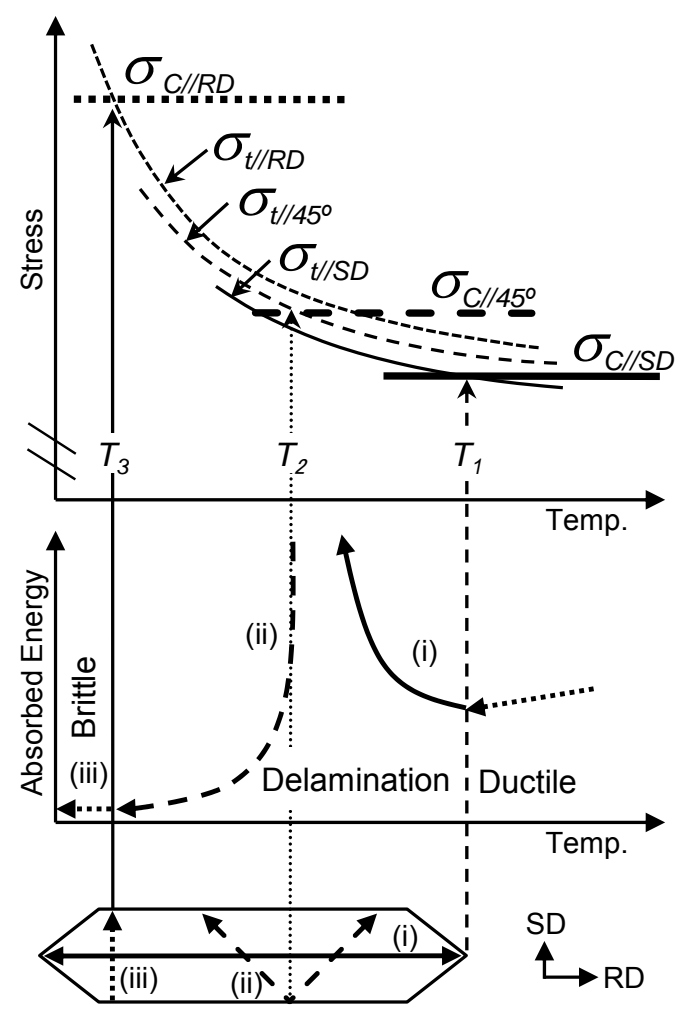

Coherence lengths on $\{100\}$ planes (i), (ii), (iii) for an elongated grain

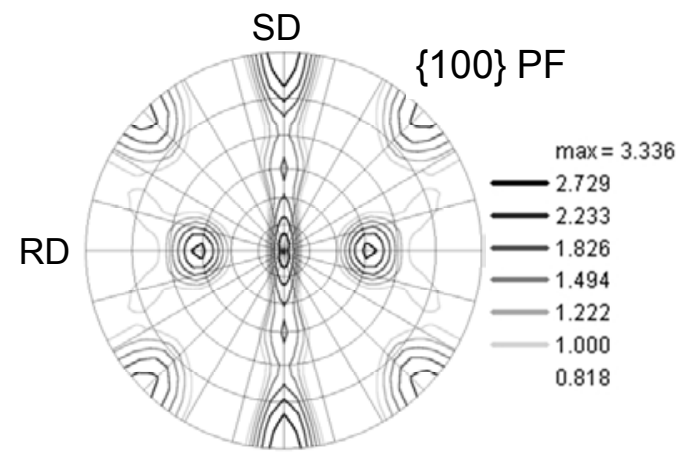

Figure 13. Yoffee diagram for UFEG structure with a strong $\{110\}$ fiber deformation texture $[14$, $15,17]$. Cleavage fractures on the longitudinal $\{100\}$ planes (/RD) cause delamination toughening (curve i), while those on the $\{100\}$ planes with the transverse components decrease the delamination toughening (curve ii). $\{100\}$ pole figure is also shown for the $0.093 \% \mathrm{P}$ steel sample. 

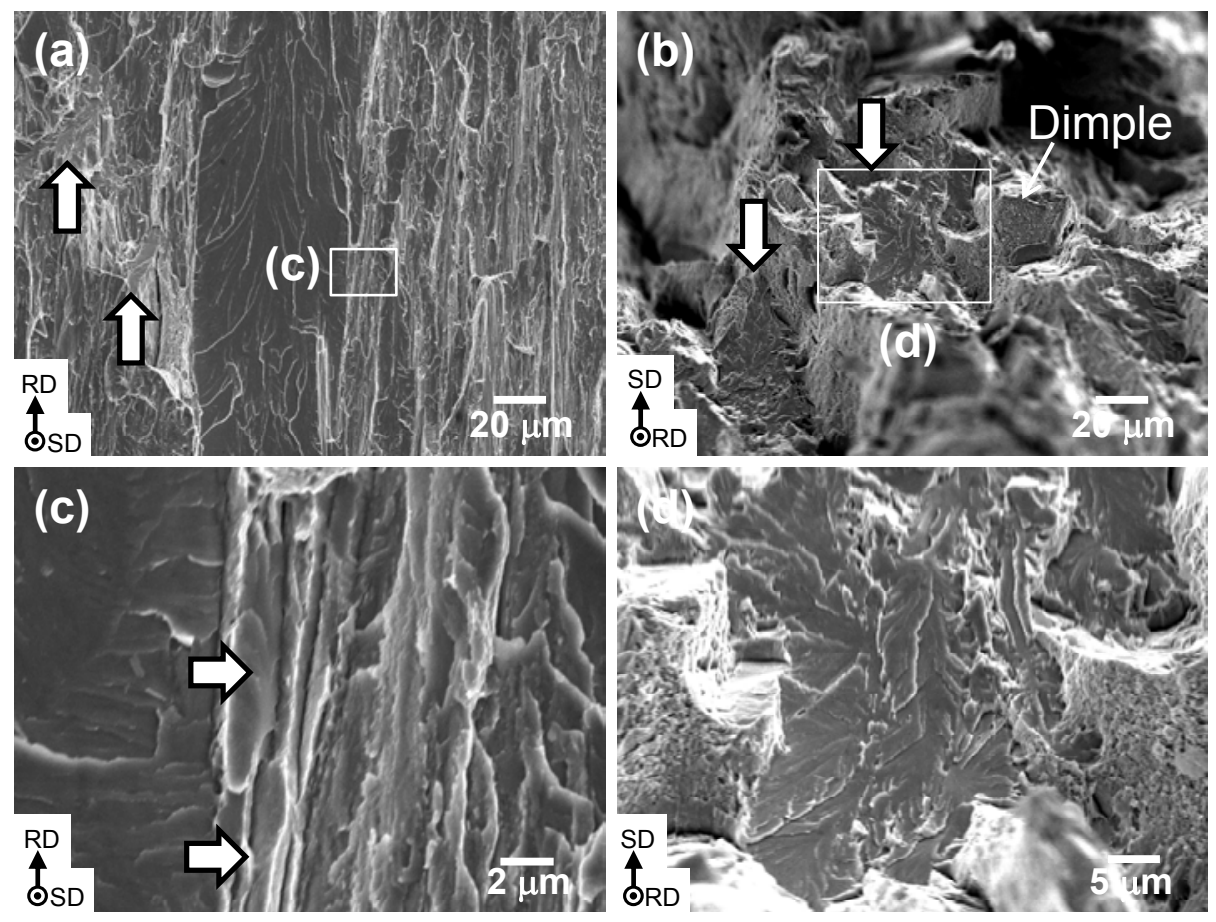

Figure 14. SEM fractrographs of the TF sample of the $0.093 \% \mathrm{P}$ steel following Charpy V-notch impact testing at $77 \mathrm{~K}$. The observed positions of (c) and (d) are marked in (a) and (b), respectively. The arrows in $(\mathrm{a}, \mathrm{b})$ and $(\mathrm{c})$ indicate the brittle transverse cracks and the cracks along the grain boundaries of the UFEG structure, respectively. 


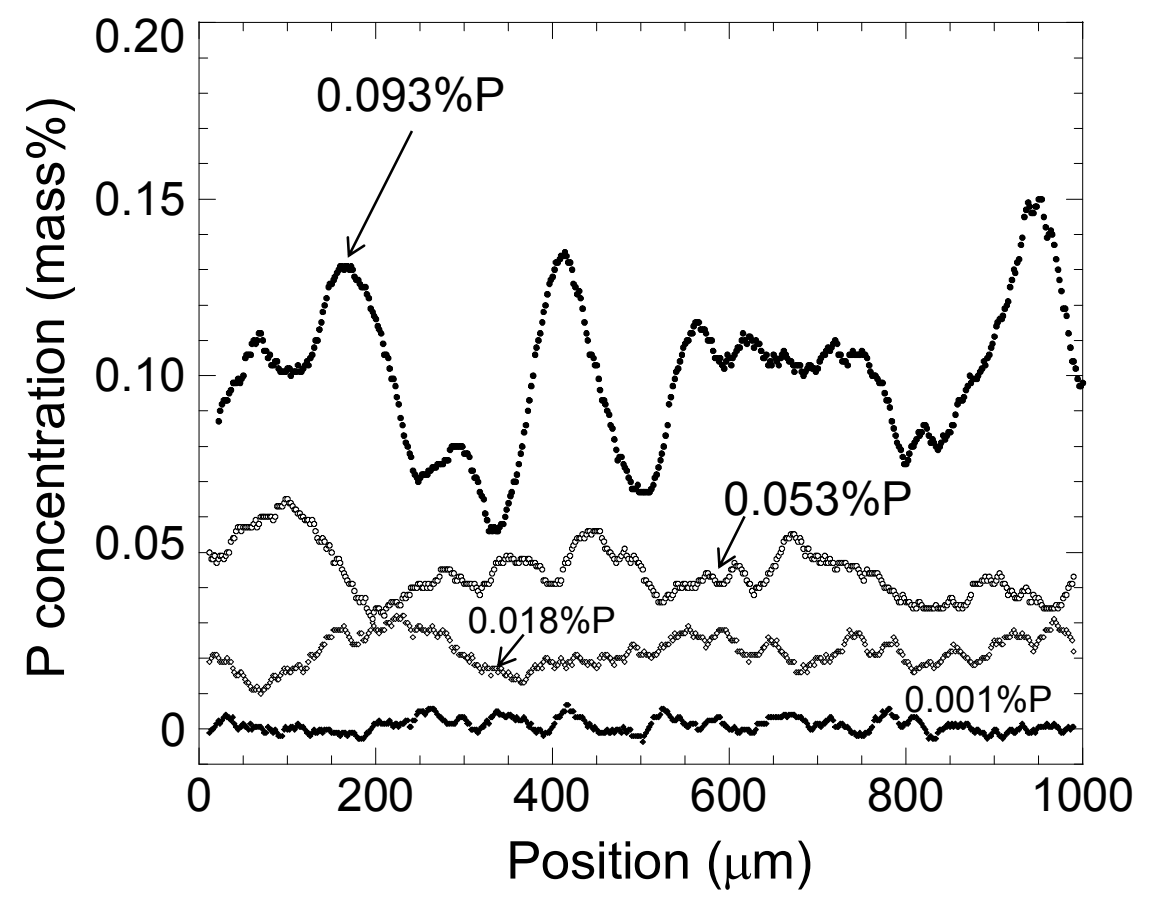

Figure15.Change in the $\mathrm{P}$ concentration line profile in the TD for the TF samples as a function of $\mathrm{P}$ concentration. 

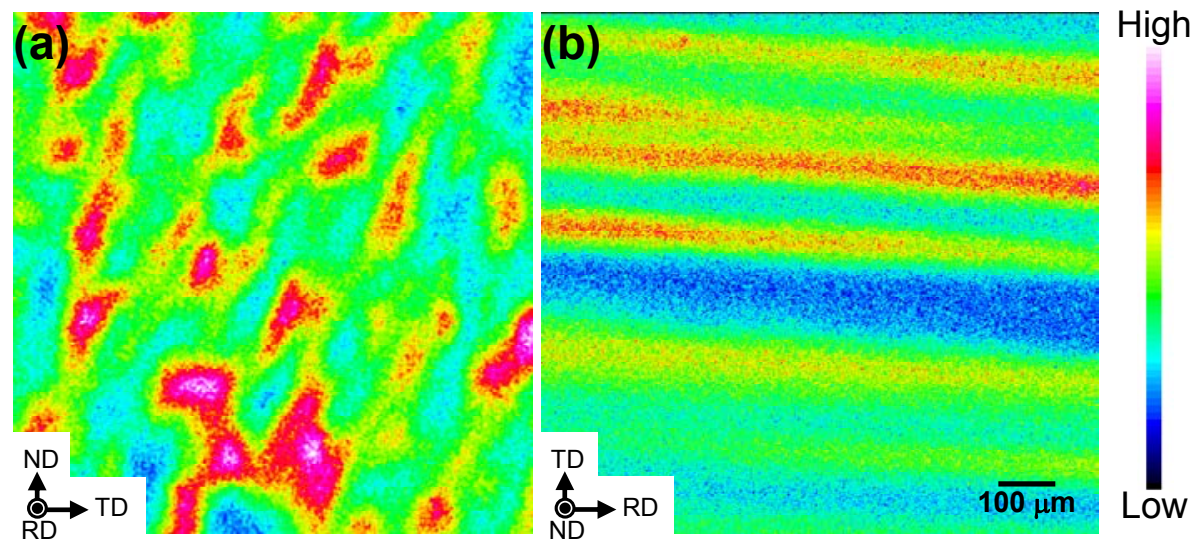

Figure16.EPMA mappings for P distribution showing the P segregation band structure for the TF $0.093 \%$ P steel sample. 